\title{
Open Educational Resources in Computer Science: Opportunities and Challenges
}

\author{
Dr. B. Ashadevi ${ }^{1}$, Prof. P. MuthamilSelvi ${ }^{2}$ \\ ${ }^{1}$ Assistant Professor / Computer Science, M.V.Muthaiah Govt. Arts College for(W), Dindigul - 01 \\ ${ }^{2}$ Assistant Professor / Computer Science, M.V.Muthaiah Govt. Arts College for(W), Dindigul - 01
}

\begin{abstract}
Open content and open access to resources are important factors in the innovation of Computer Science education. This paper presents a study aimed at gaining an understanding of the needs of Computer Science educators in terms of Open Educational Resources (OER): what kind of resources they need, when they need them, how they use them, and what are the barriers and the enablers for using OER The work contributes to the research on OER utilization and discovery. The aim is to raise the awareness and promote a practical transition process towards an adequate model that aligns the interests of all stakeholders.
\end{abstract}

Keywords: Open education, Open Educational Resources, Computer Science education, Open Source tools.

\section{Introduction}

The world is embracing an open education model. The important factors in the innovation of computer science education are open licensed educational materials and open access. Open Educational Resources (OERs) or any type of educational materials that are in the public domain or introduced with an open license that permits their free use and re-purposing by others. The nature of these open materials means that anyone can legally and freely copy, use, adapt and reassure them. OERs range from textbooks to curricula, syllabi, lecture notes, assignments, tests, projects, audio, video and animation.

The Open Educational Resources (OER) movement began in 2001 when the Hewlett and Mellon foundations jointly funded MIT's Open Course Ware (OCW) initiative. Open education is the simple and powerful idea that the world's knowledge is a public good and that technology in general and the Web in particular provide an extraordinary opportunity for everyone to share, use, and reuse knowledge.

OER are teaching, learning and research resources that reside in the public domain or have been released under an intellectual property license that permits their free use and re-purposing by others. It includes full courses, course materials, modules, textbooks, streaming videos, tests, software, and other tools, materials, or techniques used to support access to knowledge.

Despite some significant advances in recent years, OER is still not a routine part of Computer Science (CS) course development. Teaching experiences are in sharp contrast with the limited number of open related resources demonstrating them. To fill this gap, this project motivates and analyzes the evolution of the OER development and the emerging trends relevant to Computer Science education. The academic nature implies sharing knowledge and building upon ideas of others. OER provides a unique opportunity to expand the research traditions of building on the ideas of others into teaching practice. There are many observations demonstrated in [1] that educational research does not connect well with the open education practice. These observations are even more significant in the light of the following three facets of CS education which would benefit from CS OER production.

Computer Science discipline. Computer Science is dynamic. It evolves and experiences transformation, continuously. Open teaching materials, covering emerging fields can help instructors and students unfamiliar with particular topics. CS graduates spend a significant part of their career in self-learning. Providing OER can help them stay current and grow along with their chosen profession.

Computer Science career. Parallel demands come from employers. The workforce demands skills from college graduates that have to be acquired from informal learning experiences [2]. OER would enable them to learn new required skills or explore a new subject.

Computer Science, Open Source Community (OSC). OER and Open Source Software (OSS) are similar in that both rely on sharing open assets and licenses that allow to use and modify.

The aim of this paper is to gain an understanding of the needs of Computer Science educators in terms of Open Educational Resources (OER): what kind of resources 
they need, when they need them, and what are the barriers and the enablers for using OER.

\section{Patterns in OER Development}

OER are released under an intellectual property license that permits their free use or redistribution. They include learning content (full courses, course materials, content modules, learning objects, collections, and journals), tools (platforms for hosting courseware or open textbooks, online learning platforms or open learning management systems) and implementation resources (intellectual property licenses, design-principles, etc.). The term OER was later broadened to "open education" $(\mathrm{OE})$, which is the term used in the Cape Town Open Education Declaration [3]. Based on the major initiatives, OER can be grouped in the following categories:

Open courseware. OCW (https://en.wikipedia.org/wiki/) is course lessons created at universities and published for free via the Internet. OCW projects first appeared in the late 1990s, and after gaining traction in Europe and then the United States had become a worldwide means of delivering educational content. According to the website of the OCW Consortium, an OCW project: (1) is a free and open digital publication of high quality educational materials, organized as courses. (2) Is available for use and adaptation under an open license, such as certain Creative Commons licenses. (3) Does not typically provide certification or access to faculty.

MIT OpenCourseWare (ocw.mit.edu.) OCW make the materials used in the teaching of MIT's subjects available on the Web.

The Carnegie Mellon Open Learning Initiative (OLI) (oli.cmu.edu). The Open Learning Initiative (OLI) is a grant-funded group at Carnegie Mellon University, offering innovative online courses to anyone who wants to learn or teach. The aim is to create high-quality courses and contribute original research to improve learning and transform higher education.

The OpenLearn initiative (www.open.edu/openlearn/). was launched by the UK Open University to make a selection of materials available for free and to build communities of learners/educators around the content. OpenLearn complements the MIT OCW by providing not only a collection of free course materials, but also a set of tools to help authors publish and support collaborative learning communities.

Open Michigan (open.umich.edu). OpenMichigan encourages researchers, learners, and instructors to maximize the impact and reach of their scholarly work through open sharing.

Japan OpenCourseWare Consortium (JOCW) $(\boldsymbol{w} w \boldsymbol{w}$.jocw.jp). JOCW is an open and a free publication of formal course materials through the Internet. They include lecture notes, syllabi, readings, assignments, exams and video or audio lectures.

Open textbooks. Open textbook is a textbook licensed under an open copyright license, and made available online to be freely used by students, teachers and members of the public. Many open textbooks are distributed in either print, e-book, or audio formats that may be downloaded or purchased at little or no cost.

Organizations, such as Flat World Knowledge (http://www1.flatworldknowledge.com/), Panopen (https://panopen.panopen.com/), and OpenStax (http://openstax.org/), are using OER to develop free and low-cost textbooks.

\section{The following are some examples:}

College Open Textbooks (collegeopentextbooks.org). An open textbook is an integrated course-associated learning tool that is in the public domain or has been open-licensed by the copyright holder to permit re-use without the necessity of asking permission of the copyright holder. Open textbooks improve learning and teaching by freeing instructors from constantly seeking permission. Open textbooks are free or inexpensive on the web and modestly priced for downloads, use on eReaders, or in bound format.

Flat World Knowledge (catalog.flatworldknowledge.com). Instructors create the perfect book in minutes with the fast and easy online editor. Add, delete and rearrange content to match the syllabus and improve student success.

OpenStax (openstaxcollege.org). This nonprofit organization offers high-quality educational tools, and free textbooks that meet the scope and sequence requirements for most introductory courses in the selected areas. The textbooks are written by professional content developers and peer-reviewed. Currently OpenStax offers nine introductory texts used by about 140,000 students at more than 850 institutions.

Open online courses. Open online courses are an evolutionary outgrowth of two major trends: the OER movement and online learning, with its technological and pedagogical experiments (e.g., Flipped classrooms, use of multimedia), and assessment. As such, they are usually full courses with actual assignments and a similar structure to a traditional college class and allow interactive participation, including interactions between instructors and students. They are typically free 
courses, without formal entry requirements nor participation limit. Although they include interaction, feedback and assessment (via automated quizzes or peers), in general, they do not lead to official credentials. At present, open online courses are largely university-level courses.

Massively Open Online Courses (MOOCs). A MOOC is an online course aimed at unlimited participation and open access via the web. In addition to traditional course materials such as filmed lectures, readings, and problem sets, many MOOCs provide interactive user forums to support community interactions among students, professors, and teaching assistants (TAs). MOOCs are a recent and widely researched development in distance education which were first introduced in 2008 and emerged as a popular mode of learning in 2012.

Udacity (https://www.udacity.com/). Founded in 2011, Udacity (free) was the first major provider of MOOCs. Udacity offers both self-paced courses and timed programs (Nanodegrees). Free classes are solitary pursuits, lacking personalized feedback or a sense of community. Paid offerings (courses and Nanodegrees) include standardized feedback from Udacity coaches as well as verified certificates of completion.

Coursera (https://www.coursera.org/). Coursera provides universal access to the world's best education, partnering with top universities and organizations to offer courses online.

EdX (https://www.edx.org/). edX is a Massive Open Online Course (MOOC) provider. It hosts online university-level courses in a wide range of disciplines to a worldwide student body, including some courses at no charge. It also conducts research into learning based on how people use its platform. EdX differs from other MOOC providers, such as Coursera and Udacity, in that it is a nonprofit organization and runs on open-source software. The Massachusetts Institute of Technology and Harvard University created edX in May 2012. More than 70 schools, nonprofit organizations, and corporations offer or plan to offer courses on the edX website. As of 24 March 2016, edX has more than 7 million students taking more than 700 courses online.

OpenUpEd (http://www.openuped.eu). OpenupEd is, worldwide, one of the largest MOOC providers of higher education. MOOCs to be:

- online courses designed for large numbers of participants,

- That can be accessed by anyone, anywhere as long as they have an internet connection,

- Are open to everyone without entry qualifications,
- And offer a full/complete course experience online for free.

Open tools and Open Source software (OSS) as a platform and as a model. OER include also tools to develop, use and distribute the content [5]. In this aspect, OSS plays a dual role: as a platform for building tools and as a model for guiding OER development. Tools allow content downloading, configuration and customization, as well as publishing, use, evaluate or adoption of resources. The examples are platforms for open online courses and for hosting open textbooks, courseware and OER repositories. The OER principles were inspired by the OSS movement. For example, the OSS development model was used to guide the design of Connexions (cnx.org), a platform for creating, storing, remixing and sharing peer-produced modular learning content.

Implementation resources. Implementation resources refer to intellectual property, design-principles, and localization of content [5]. The licensing options as defined by Creative Commons (creativecommons.org) enable the sharing and use of knowledge through free legal tools. There are four types of Creative Commons licenses distinguished by the following features [4]:

- Attribution (BY). This allows users to copy, distribute and display the work and make derivative works, as long as the author is given the credits for the original creation.

- Share-Alike (SA). This allows users to distribute derivative works only under a license identical to the license that governs the original work.

- Noncommercial (NC). This allows users to copy, distribute, display the work and make derivative works based on it, only for noncommercial purposes.

- No Derivative work (ND). This allows users to copy, distribute and display the work, but not to make derivative works. These features are combined in different ways to create six Creative Commons licenses, which define a spectrum of copyright permissions for creative work.

\section{Opportunities of OER in CS}

OERs are "digital learning resources offered online freely and openly to teachers, educators, students, and independent learners in order to be used, shared, combined, adapted, and expanded into teaching, learning and research.", OECD, 2012. The term was first introduced at the 1st Global OER conference hosted by UNESCO in 2002. By providing open access to course content, the development of OER initiatives has paved the way for free online courses, such as OCW and MOOC 
(https://epthinktank.eu/2013/10/01/open-educationoer-ocw-and-moocs/).

OER initiatives aspire to provide free access to highquality educational resources on a global scale. They are:

- Educational materials (lectures, textbooks, streaming videos, multimedia applications, podcasts, curriculum outlines, etc.);

- Aimed at all educational levels (primary to third level, lifelong learning);

- Freely available via open digital repositories (eg OER Commons);

- Produced by educators;

- Intended for students and teachers/trainers alike, to be used in their teaching \& learning activities.

OERs exist within the wider 'Openness' movement, based on the idea that knowledge should be disseminated and shared freely through the Internet for the benefit of society as a whole. The two most important aspects of openness are freely available and as few restrictions as possible on the use of the resource, whether technical, legal or price barriers.

OER initiatives have resulted in the development of open access courses in higher education: OCWs and MOOCs. This infographic provides an overview of the rapid rise of online learning.

OpenCourseWare $(\mathrm{OCW})$ is a "free and open digital publication of university-level educational materials. These materials are organized as courses, and often include course planning materials and evaluation tools as well as thematic content" (OCW Consortium). MIT's OCW programme started in 2001.

MOOCs (Massive Open Online Courses) are free online courses without formal entry requirement nor participation limit. They include interaction, feedback and assessment (via automated quizzes or peers) but do not lead to official credentials/ do not currently earn credits. Currently, most of the MOOC movement is based in the US, although some European universities have joined US initiatives, and recently a paneuropean MOOC platform has been launched, OpenupEd, as well as some national initiatives in Member States, e.g. Future Learn LTD in the UK. It started in 2012 when a number of prominent US universities began offering them, eg: Coursera, developed by Stanford University; eDx, funded by MIT and Harvard University. These are sometimes referred to as xMOOCs, to differentiate them from an earlier version, the cMOOCs. While in the latter the instructor acts as a coach for participants formulating their own learning outcomes, xMOOCs are content-based, with the lecture as their didactic model.

\subsection{Computer Science OER production}

From an institutional perspective, the interest in OER and specifically CS OER is lower compared to MOOCs. From 22,123 universities around the world (http://www.webometrics.info/en/node/54) only 46 include Computer Science resources in their OER repositories [6]. According to the U.S. Department of Education

(http://nces.ed.gov/fastfacts/display.asp?id=84) the total number of the US four year universities was 2,870 in 2011. From these, 19 universities are offering OER (https://www.oercommons.org/oer/providers), which is about $0.7 \%$ of the total number. A closer look reveals that only six universities actually offer CS resources, while the total number of universities offering CS degree is 787 (which is again about $0.6 \%$ of the total number of universities offering CS degree). The development of OSS can be considered as a form of online knowledge sharing. According to Lerner and Tirole [7], about 2.1 million US citizens had a computer science job at the beginning of this millennium. They also note that of the potential 2.1 million contributors to the open source community, about 13,000 people (or $0.62 \%$ ) actually contributed some code. Likewise, according to a recent study [8] about $0.87 \%$ of the registered Wikipedians are considered active (contributing) users. Since our observations are consistent with the data from related open initiatives, it is perhaps unrealistic to expect that the number of the CS OER resources will grow significantly without extra energizing factors.

Although MOOCs are not strictly OER, they grew from OER roots and epitomize a move towards greater accessibility of higher education. Most notably, MOOCs have shown that when the educational resources are set within the right framework and embedded properly in the educational ecosystem, they have the capacity to change the way the content is produced and shared. Thus MOOCs provide CS educators with a vehicle to think creatively and explore new pedagogical practices, business models and learning paths in their provision.

\subsection{The impact of Computer Science on OER evolution}

From open access to OER, and more recently, open online courses and MOOCs, there is growing momentum for the CSE community to participate in the open movement. The following facts are a manifestation of the role of this community in the process. 
The turning point in MOOCs was 2011, when Stanford CS professors offered three of the school's most popular CS courses as MOOCs - Machine Learning, Introduction to Artificial Intelligence and Introduction to Databases. The Introduction to AI (taught by Sebastian Thrun and Peter Norvig) was a really massive course attracting 160,000 students from over 190 countries. Coursera is also founded by Stanford CS professors, Andrew $\mathrm{Ng}$ and Daphne Koller [9]. Launched in April 2012 as an educational technology company offering MOOCs, by February 2013 Coursera had over 69 university partners offering courses in Chinese, Italian and Spanish. According to statistics compiled in 2013 [10] 27\% of the MOOC courses are in Computer Science. Similarly, science and technology MOOCs are the largest number of MOOCs in Europe [11]. More interesting is that Georgia Tech, Udacity, and AT\&T have teamed up to offer an online Master's degree in CS $\square$ the first of its kind delivered through a MOOC. As an alternative, Coursera offers specializations (Data science, Android, Cyber Security and Fundamentals of Computing) [12] that allow students to follow university-led tracks and attain mastery in a particular subject.

On the major providers, the opportunity to teach MOOCs has been an invite only proposition to established universities and professors. But new platforms, such as OpenEdX and MOOC.org can make this more easily available. OpenEdX is the open-source release of edX, while MOOC.org is a partnership between open EdX and Google to create a MOOC authorship platform. The quick rise in textbook prices has not been ignored by the CS educators. Allen Downey's "Think" series (http://greenteapress.com/) is one of the earliest examples of open textbooks [13]. Starting with introductory CS texts using Java and Python, it has grown to cover a large range of related topics. The positive attitude towards open textbooks is demonstrated by the fact that from total 811 open textbooks, 127 are CS textbooks (collegeopentextbooks.org).

Another dimension in the OER evolution is the collaborative development of educational content similar to OSS. While OSS relies on collaborative work, there are only two examples of OER that do rely on collaborative development: Wikieducator and Curriki. Several authors suggested the social codesharing network GitHub as a tool for managing the OER production process. The idea is to use GitHub with open educational content as the "code" to share. Similar to the OSS community model it will facilitate a culture of structured collaboration and improvement. A good example in this direction is Coursefork [14], a platform for open-sourcing and collaborating on courseware creation. It enables authors to upload course material, create copies, modify them and share the improvements. Coursefork's goal is to replace closed systems with open systems in the world of education.

Another evidence (developers.google.com/edu/curriculumsearch/) for the growing interests in OER and in particular in the CS OER is the Google Curriculum Search. A collaboration between Google and its academic partners, Curriculum Search helps users find teaching materials that have been published by faculty from CS departments around the world. Also, the OER Foundation has been selected as a mentor organization for this year's Google Summer of Code [15].

\subsection{Challenges to the Growing OER Movement}

Although the idea of OER is thriving at the moment, it is important also to look at some challenges that might stifle the further growth of the movement. In this project, the challenges will be touched upon: the lack of awareness among academics regarding copyright issues; how doing web access for disabled people.

Lack of awareness of copyright issues. While publication, consumption and distribution of texts were mediated through physical media, academics remained for the most part unaware of the licensing that underpinned the exploitation of copyright. The internet and other digital media have changed this. The most part they seem either unprepared or unwilling to engage with cumbersome licensing procedures.

Although many academics are willing to share their work, they are often hesitant as how doing this without losing all their rights. Although some people release work under the public domain, it is not unusual that authors would like to retain some rights over their work. The RoMEO project in UK made a survey in 2002-2003 among 542 researchers about what kind of rights they wanted to retain. [15] A majority (over $60 \%$ ), were happy for third parties to display, print, save, excerpt from and give away their papers, but wanted this to be on the condition that they were attributed as the authors and that all copies were done so verbatim. $55 \%$ wanted to limit the usage of their works to educational and non-commercial use. The RoMEO report concluded that the protection offered to research papers by copyright law is in excess of what is required by most academics.

Several open content licenses have been developed, like the Creative Commons and the GNU Free Documentation Licence, to accommodate this problem. Open licensing provides a way of controlled sharing with some rights reserved to the author. They have the 
benefit of introducing certainty and clarity into the process of obtaining permission to use the work of others. They also reduce the administrative burden of having to clear the rights before use. This is particularly useful in the educational context where users have little or no inside knowledge of the mechanisms used by the media industries. Finally, open licenses, establish a body of works licensed as "open content" that may be freely shared. However, it must also be recognized that they have some disadvantages. Rights holders must be prepared to grant and to live with exercising only a "broad-sweep" control over their works, replacing the case by case control with which they are familiar. Moral rights are waived under licenses offering the right to make derivative works and different and often blurred and overlapping boundaries emerge between not-for-profit, educational and commercial exploitation or distribution. Despite some shortcomings, there seems to be a growing interest for open licenses, as shown by the increasing number of objects released under the Creative Commons license.

The RoMEO project also showed that $41 \%$ of authors "freely" assign copyright to publishers without fully understanding the consequences. Preliminary findings from the OECD survey on OER shows a low awareness regarding the importance of using open licenses among teachers and researchers producing learning resources, and few initiatives from institutions to accommodate this deficiency. Given that the scholars in the RoMEO survey and those responding the OECD questionnaire are more or less representative of academics from other countries, the conclusions seems to strengthen the assumption that raising the awareness on copyright and licenses is an important challenge for both the OER and $\mathrm{OA}$ movements. Maybe even easier ways of retaining only those rights that the individual author wants to retain are needed, together with active advice and support from higher educational institutions. A recent comparison of seven Australian universities underpins previous international research showing that relying solely on voluntary deposits by academics of research articles to $\mathrm{OA}$ archives will result in approximately $15 \%$ contribution.

Web access for disabled people: Since many OER projects have as their mission to broaden access to digital learning resources, people with disabilities of different kinds should be considered. Even though the Internet offers unprecedented access to information and interaction, most websites and web software still have accessibility barriers that make it difficult or impossible for millions of people with disabilities to use the Internet. The accessibility barriers to print, audio and visual media can be overcome. The Web Accessibility Initiative of the World Wide Web Consortium looks at how different disabilities affect access to the Internet and what can be done to overcome these difficulties. As more accessible websites and software become available, people with disabilities will be able to use and contribute to the Internet more effectively.

A key principle of web accessibility is to design websites and software that are flexible enough to meet different user needs, preferences and situations. This also benefits people without disabilities in certain situations, such as people using a slow Internet connection, people with "temporary disabilities" such as a broken arm, and people with changing abilities due to aging. One of the roles of the Web Accessibility Initiative is to develop guidelines and techniques describing accessibility solutions for Internet software and developers that could be very useful for OER initiatives.

Examples of design requirements for people with different kinds of disabilities include:

- Visual: Descriptions of graphics or video; well marked-up tables or frames; keyboard support, and screen reader compatibility.

- Hearing: Captioning for audio, supplemental illustration.

- Physical, speech: Keyboard or single-switch support; alternatives for speech input on voice portals.

- Cognitive, neurological: Consistent navigation, appropriate language level; illustration; no flickering or strobing designs. Accessible web design contributes to better design for other users as well. Illustrations given by the Web Accessibility Initiative include multi-modality (support for visual, auditory, tactile access) which benefits users of mobile phones with small display screens and Web-TV. It also increases usability of websites in situations with low bandwidth (images are slow to download); noisy environments (difficult to hear the audio); screen glare (difficult to see the screen); driving (when eyes and hands are "busy"). Other illustrations of accessible web design are redundant text, audio and video which can support different learning styles, low literacy levels and second-language access. Additionally, style sheets can support more efficient page transmission and site maintenance. Captioning of audio files, supports better machine indexing of content and faster searching of content.

\section{Conclusions}

Although the OER phenomenon is very recent, it is the subject of growing interest. No definite statistics are available, but it has expanded in terms of number of projects, number of people involved and a number of resources available. It is a global developer, although most resources are currently produced in developed 
countries. Developments and trends in CS OER mirror advances are occurring within OER in general. As OER and its derivatives are still in the early stages of development, further research is needed on issues, such as barriers, practices and business models to expand their opportunities.

\section{REFERENCES}

[1] G e s e r, G. Open Educational Practices and Resources. Salzburg Research. EduMedia Group.

[2] J o hn s o n, L., S. A. B e c k e r, M. Cu m min s , V. E s tr a d a, A. Fre e m a n, H. Lu d g a t e. NMC Horizon Report: Higher Education Edition. Austin, Texas, The New Media Consortium, 2013.

[3] Mu 1 d e r, F., B. J a n s s e n. Opening up Education. - In: Trend Report OER. SURF SIG OER, Utrecht, 2013, pp. 36-42.

[4] C h e u n g, S. K. S., K. C. L i, K. S. Y u e n. An Overview of Open Educational Resources for Higher Education. - In: Intl. Conference on ICT in Teaching and Learning, HKU Space, 2013.

[5] OECD. Giving Knowledge for Free. The Emergence of Open Educational Resources. Paris, OECD Publishing, 2007.

[6] Listing of University and Colleges Offering OER. http://libguides.tcc.edu/content.php? pid=5520

$69 \& \operatorname{sid}=4550325$

[7] L e r n e r, J., J. T i r o l e. Some Simple Economics of Open Source. - Journal of Industrial Economics, Vol. 2, 2002, pp. 197-234.

[8] We b e r, S. The Success of Open Source. Cambridge, Mass., Harvard University Press, 2004.

[9] K a m e n e t z, A. How Coursera, a Free Online Education Service, Will School Us All. Fast Company, August 2012.

http://www.fastcompany.com/3000042/how-

coursera-free-online-education-service-willschool-us-

all

[10] K i n g, W. J., M. N a n f i t o. MOOCs for the Rest of US: An Inside Higher Ed. Webinar. National Institute for Technology in Liberal Education.

[11] European MOOCs Scoreboard Open Education Europa.

http://www.openeducationeuropa.eu/en/europe

an_scoreboard_moocs

[12] http://blog.coursera.org/post/73994272513/coursera -specializations-focused-programs-in

[13] S i $m$ i a n, P. Prereqs - not MOOC-Wrecks! Hitting the Books. Class Central, October 2014.

https://www.class-central.com/report/prereqs-

mooc-wrecks-hitting-books/

[14] H i b b e t s, J. Coursefork: A New Way to Collaborate on Open Education. Red Hat. September 2013.

http://opensource.com/education/13/9/courseforkeducation-tool
[15] Computer Science Students: Apply to Mentor with OER Foundation for Google Summer of Code. Bccampus, 2014.

bccampus.ca/2014/02/26/computer-science-studentsapply-to-mentor-with-oerfoundation-for-google-

summer-of-code/

[16] Gadd, E., Oppenheim, C., Probets, S.,: (2003) RoMEO Studies 2: "How academics want to protect their open-access research papers" Department of Information Science, Loughborough University from

http://www.lboro.ac.uk/departments/ls/disresearch/r omeo/RoMEO\%20Studies\%202.pdf

\section{Websites:}

1. https://en.wikipedia.org/wiki/

2. ocw.mit.edu

3. oli.cmu.edu

4. www.open.edu/openlearn

5. open.umich.edu

6. www.jocw.jp

7. http://www1.flatworldknowledge.com/

8. https://panopen.panopen.com/

9. http://openstax.org/

10. collegeopentextbooks.org

11. catalog.flatworldknowledge.com

12. openstaxcollege.org.

13. https://www.udacity.com

14. https://www.coursera.org

15. https://www.edx.org/

16. http://www.openuped.eu

17. https://epthinktank.eu/2013/10/01/open-educationoer-ocw-and-moocs/

Ashadevi. B received Bachelor's degree in Computer Science and MCA from Madurai Kamaraj University. She received her M.Phil and Ph.D. in computer Science from Mother Teresa Women's University Kodaikanal. She has more than 17 years of experience in the field of computer science. Her research interest in Data Warehousing and Data Mining. She has published many research papers and presented more than 15 papers in national and international journals. She is a life member of ISTE. She has organized National level conferences. She has organized guest lectures, Seminars, and workshops for post graduates students of Computer Applications and Computer Science. She has supervised several MCA project works and M.Phil thesis.

MuthamilSelvi. P Completed B.sc., MCA., and M.Phil from Madurai Kamaraj University. She has more than 12 years of experience in the field of computer science. 
Her area of interest include Neural networks and Fuzzy logic, Collaborative learning, Cloud Computing, and Big data. She has published many research papers and presented more than 15 papers in national and international journals. She has published many research articles and presented more than 15 papers in national and international journals. She has organized seminars and workshops. 